\title{
Comparative efficacy of tandem autologous versus autologous followed by allogeneic hematopoietic cell transplantation in patients with newly diagnosed multiple myeloma: a systematic review and meta-analysis of randomized controlled trials
}

Mohamed A Kharfan-Dabaja ${ }^{1,2}$, Mehdi Hamadani ${ }^{3}$, Tea Reljic ${ }^{4}$, Taiga Nishihori ${ }^{1}$, William Bensinger ${ }^{5}$, Benjamin Djulbegovic ${ }^{4,6,7}$ and Ambuj Kumar ${ }^{4,6,7^{*}}$

\begin{abstract}
Background: Despite advances in understanding of clinical, genetic, and molecular aspects of multiple myeloma (MM) and availability of more effective therapies, MM remains incurable. The autologous-allogeneic (auto-allo) hematopoietic cell transplantation (HCT) strategy is based on combining cytoreduction from high-dose (chemo- or chemoradio)-therapy with adoptive immunotherapy. However, conflicting results have been reported when an auto-allo HCT approach is compared to tandem autologous (auto-auto) HCT. A previously published meta-analysis has been reported; however, it suffers from serious methodological flaws.

Methods: A systematic search identified 152 publications, of which five studies (enrolling 1538 patients) met inclusion criteria. All studies eligible for inclusion utilized biologic randomization.

Results: Assessing response rates by achievement of at least a very good partial response did not differ among the treatment arms [risk ratio $(\mathrm{RR})(95 \% \mathrm{Cl})=0.97(0.87-1.09), \mathrm{p}=0.66$ ]; but complete remission was higher in the auto-allo $\mathrm{HCT}$ arm [RR $=1.65$ (1.25-2.19), $\mathrm{p}=0.0005]$. Event-free survival did not differ between auto-allo HCT group versus auto-auto HCT group using per-protocol analysis [hazard ratio $(H R)=0.78(0.58-1.05)), p=0.11$ ] or using intention-to-treat analysis [HR=0.83 (0.60-1.15), $\mathrm{p}=0.26]$. Overall survival (OS) did not differ among these treatment arms whether analyzed on per-protocol $[H R=0.88(0.33-2.35), p=0.79]$, or by intention-to-treat [HR=0.80 (0.48-1.32), $p=0.39]$ analysis. Non-relapse mortality (NRM) was significantly worse with auto-allo HCT [RR (95\%Cl) $=3.55(2.17-5.80), p<0.00001]$. (Continued on next page)
\end{abstract}

\footnotetext{
* Correspondence: Akumar1@health.usf.edu

${ }^{4}$ Center for Evidence-Based Medicine and Health Outcomes Research, University of South Florida, Morsani College of Medicine, 12901 Bruce B. Downs Boulevard, MDC 27, Tampa, FL 33612, USA

${ }^{6}$ Department of Health Outcomes and Behavior, Moffitt Cancer Center,

Tampa, FL, USA

Full list of author information is available at the end of the article
} 
(Continued from previous page)

Conclusion: Despite higher complete remission rates, there is no improvement in OS with auto-allo HCT; but this approach results in higher NRM in patients with newly diagnosed MM. At present, totality of evidence suggests that an auto-allo HCT approach for patients with newly diagnosed myeloma should not be offered outside the setting of a clinical trial.

Keywords: Autologous hematopoietic stem cell transplantation, Allogeneic hematopoietic stem cell transplantation, Multiple myeloma, Systematic review

\section{Background}

The past two decades witnessed major advances in treatment of multiple myeloma (MM), including introduction of high-dose therapy (HDT) (chemotherapy or chemoradiotherapy), autologous hematopoietic cell transplantation (auto-HCT), and other effective therapies including immunomodulatory drugs or proteasome inhibitors, namely bortezomib [1-5]. These new chemotherapeutic agents when used in combinations, have led to improvement in survival and a higher frequency and better quality of response; but have not translated into cure of this disease $[3,4]$.

The concept of "total therapy" treatment approach for patients with newly diagnosed MM, using multi-agent induction regimens, tandem auto-auto HCT, and posttransplantation maintenance resulted in progressive increase in proportion of patients achieving complete remission (CR) [6]. The Intergroupe Francophone du Myelome (IFM) demonstrated that tandem auto-auto HCT improves overall survival (OS) among patients with myeloma, particularly if a very good partial response (VGPR) is not achieved after undergoing the first autoHCT [7]. A meta-analysis by our group showed that tandem auto-auto HCT versus single auto-HCT in previously untreated MM results in improved response rates, but not improved OS [8].

Badros et al. demonstrated the feasibility of offering reduced-intensity conditioning (RIC) allogeneic (allo)-HCT as a salvage strategy in 31 patients with relapsed MM [9]. Seventeen (55\%) of 31 cases had received at least two autoHCT and 17 (55\%) had progressive disease at time of allografting [9]. Despite these adverse clinical features, 19 (61\%) patients achieved CR or a near CR, with the 100-day and overall non-relapse mortality (NRM) of $10 \%$ and $29 \%$, respectively [9]. This suggests a beneficial graftversus-myeloma (GVM) effect mediated by alloreactive donor T-cells is capable of disease control, even in MM refractory to HDT. Gahrton et al. compared outcomes of patients who received allo-HCT for relapsed MM during 1983-1993 and 1994-1998 showing improvement in NRM and OS for patients allografted during the later time period [10]. The authors speculate that earlier time to allografting (10 months versus 14 months), for patients transplanted during the later time period, probably contributed to this beneficial effect [10]. Similar results were recently reported by Kumar et al., where 1 year OS post allo-HCT improved in three successive eras (1989-1994, 1995-2000, and 2001-2005) and increased interval between time of MM diagnosis and allografting was found to be an independent adverse prognostic factor for OS [11].

Combining benefits of cytoreductive-therapy from HDT and auto-HCT with adoptive immunotherapy (from allo-HCT) forms the basis of auto-allo HCT treatment strategy in patients with MM. Conflicting results, however, have been noted when an auto-allo HCT approach has been compared to an auto-auto HCT strategy. A recent systematic review on the same issue was performed by Armeson et al. [12] However, this systematic review is limited by inclusion of an inappropriate study, in our opinion. That is, this systematic review included the study by Garban et al. which was not a true randomized controlled trial but rather represents comparisons from two parallel trials (IFM99-03 and IFM99-04) that enrolled allograft and autograft recipients separately. Most importantly, the systematic review by Armeson et al. did not attempt to evaluate the methodological quality of included studies, which is the one of the key reasons to conduct a systematic review. Assessment of risk of bias in the systematic review process provides explanations on whether the observed findings are indeed the effect of the intervention or as a result of bias. Accordingly, we performed a systematic review of published studies comparing auto-auto HCT with auto-allo HCT in patients with newly diagnosed MM that addresses all the issues that were not addressed in the systematic review by Armeson et al.

\section{Results}

Initial search yielded 152 references and 2 abstracts, of which 149 were excluded for various reasons as shown in Figure 1. Five studies (four full-manuscripts and one abstract) enrolling a total of 1538 patients were eligible for inclusion into this meta-analysis [13-17]. In one case [15], we identified a complementary publication [18] which provided longer follow-up on the originally published study. Additionally, we excluded one manuscript [19] because it was an indirect comparison (i.e. patients were enrolled separately into two parallel trials, IFM99-03 and IFM99-04, 


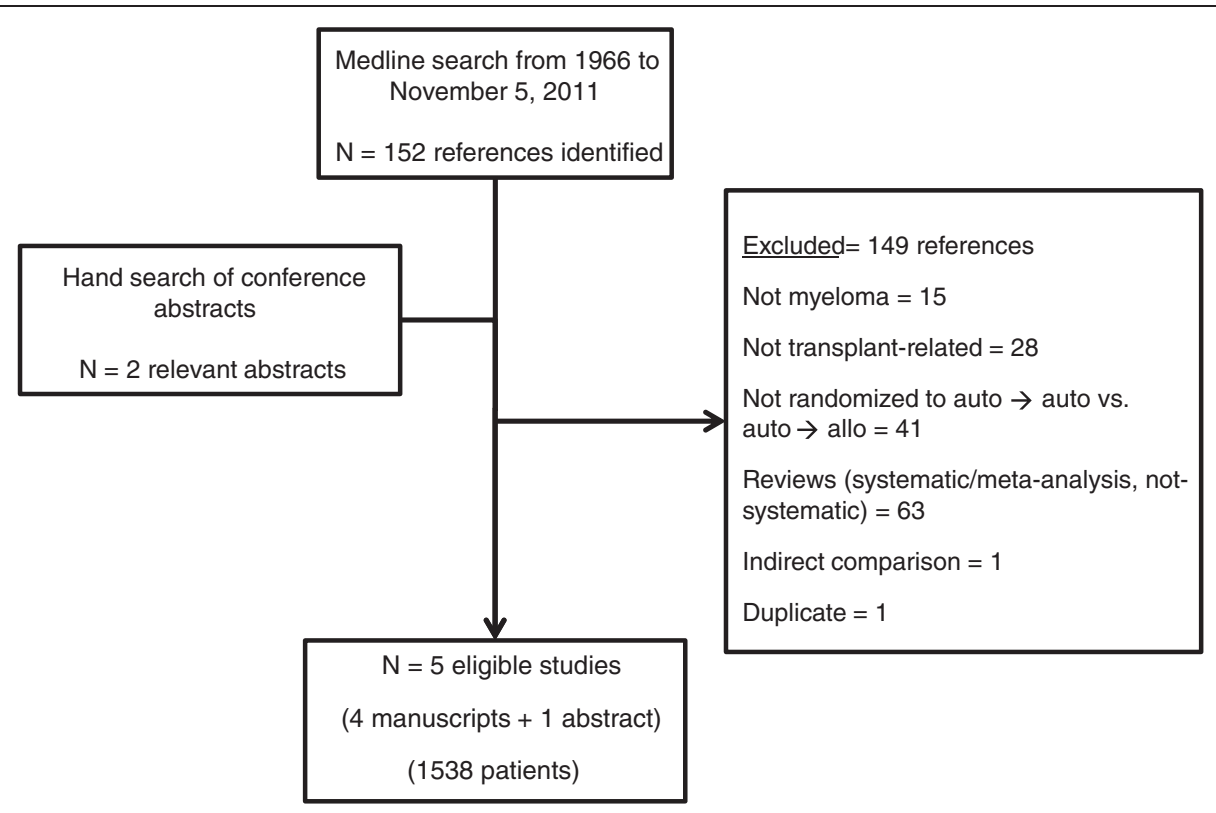

Figure 1 Flow-diagram depicting the identification and selection of eligible studies for inclusion in the systematic review.

with different primary endpoints and subsequently compared to each other). Finally, we excluded one abstract, HOVON50/54, because patients on the control arm received only a single auto HCT [20].

\section{Patient, disease and treatment characteristics}

Table 1 summarizes extracted data pertinent to patients/ disease and treatment characteristics. All studies allocated patients to auto-allo HCT if an HLA-matched sibling donor was available, except one [16] where matched volunteer unrelated donors were permitted. For patients undergoing tandem auto-auto HCT, high-dose melphalan
$200 \mathrm{mg} / \mathrm{m}^{2}$ (MEL200) was the preferred regimen for the first autograft in three studies $[13,14,16]$, melphalan dose ranging from 100 to $200 \mathrm{mg} / \mathrm{m}^{2}$ was used in one study [15], and melphalan dose ranging from 140 (with total body irradiation) to $200 \mathrm{mg} / \mathrm{m}^{2}$ was used in another study [17]. For the second autograft, MEL200 was the preferred regimen in two studies $[13,16]$. In the study by Bruno et al. patients were offered a dose of melphalan ranging from 100 to $200 \mathrm{mg} / \mathrm{m}^{2}$ [15], whereas Rosiñol et al. allowed MEL200 or a combination of cyclophosphamide, etoposide, BCNU [17]. Moreover, Björkstrand et al. provided patients the option to undergo a second

Table 1 Characteristics of biologically randomized studies in tandem autologous versus autologous-allogeneic hematopoietic cell transplantation for patients with multiple myeloma

\begin{tabular}{|c|c|c|c|c|c|c|}
\hline Study & $\begin{array}{l}\text { Publication } \\
\text { type }\end{array}$ & Disease stage & $\begin{array}{l}\text { Disease } \\
\text { risk }\end{array}$ & Donor & Auto-allo regimen & Auto-auto regimen \\
\hline $\begin{array}{l}\text { Björkstrand, } \\
2011\end{array}$ & Full text & $\begin{array}{c}\text { DSS stage: I - } 44 \\
(12 \%) \|-55(16 \%)|| \mid- \\
253(72 \%)\end{array}$ & Various & $\begin{array}{l}\text { HLA matched } \\
\text { sibling donor }\end{array}$ & $\begin{array}{l}\text { MEL } 200 \mathrm{mg} / \mathrm{m} 2 \rightarrow \\
\quad 2 \text { Gy TBI + FLU }\end{array}$ & $\begin{array}{c}\text { MEL } 200 \mathrm{mg} / \mathrm{m}^{2} \times 2 \text { (or MEL } 200 \mathrm{mg} / \\
\mathrm{m}^{2} \rightarrow \text { no transplant (a second auto- } \\
\text { HCT was optional) }\end{array}$ \\
\hline $\begin{array}{l}\text { Bruno, 2007/ } \\
\text { Giaccone, } \\
2011\end{array}$ & Full text & $\begin{array}{l}\text { DSS stage: II - } 48 \\
(30 \%) \text { III - } 114(70 \%)\end{array}$ & Various & $\begin{array}{l}\text { HLA matched } \\
\text { sibling donor }\end{array}$ & $\begin{array}{c}\text { MEL } 200 \mathrm{mg} / \mathrm{m} 2 \rightarrow \\
2 \mathrm{~Gy} \mathrm{TBI}\end{array}$ & $\begin{array}{l}\text { MEL 100, } 140 \text { or } 200 \text { mg/m2 } \rightarrow \\
\text { MEL100, } 140 \text { or } 200 \text { mg/m2 }\end{array}$ \\
\hline Knop, 2009 & Abstract & DSS stage: II and III & $\begin{array}{l}\text { Limited } \\
\text { to } 13 q^{-}\end{array}$ & $\begin{array}{l}\text { HLA matched } \\
\text { sibling or } \\
\text { unrelated donors }\end{array}$ & $\begin{array}{c}\text { MEL } 200 \mathrm{mg} / \mathrm{m} 2 \rightarrow \\
\text { FLU-MEL } 140 \mathrm{mg} / \mathrm{m} 2 \pm \\
\text { ATG }\end{array}$ & MEL 200 mg/m2 x 2 \\
\hline $\begin{array}{l}\text { Krishnan \& } \\
\text { Pasquini, } \\
2011\end{array}$ & Full text & $\begin{array}{l}\text { DSS stage: I-II - } 201 \\
(32 \%) \text { III - } 424(68 \%)\end{array}$ & Various & $\begin{array}{l}\text { HLA matched } \\
\text { sibling donor }\end{array}$ & $\begin{array}{c}\text { MEL } 200 \mathrm{mg} / \mathrm{m} 2 \rightarrow \\
2 \mathrm{~Gy} \mathrm{TBI}\end{array}$ & MEL $200 \mathrm{mg} / \mathrm{m} 2 \times 2$ \\
\hline $\begin{array}{l}\text { Rosiñol, } \\
2008\end{array}$ & Full text & $\begin{array}{c}\text { ISS stage: | }-42(40 \%) \\
\text { || - } 48(46 \%) \text { ||I - } 14 \\
(14 \%)\end{array}$ & Various & $\begin{array}{l}\text { HLA matched } \\
\text { sibling donor }\end{array}$ & $\begin{array}{l}\text { MEL } 200 \mathrm{mg} / \mathrm{m} 2 \text { or } \\
\text { MEL } 140 \mathrm{mg} / \mathrm{m} 2+ \\
\quad \mathrm{TBI} \rightarrow \text { FLU-MEL }\end{array}$ & $\begin{array}{c}\text { MEL } 200 \mathrm{mg} / \mathrm{m} 2 \text { or MEL } 140 \mathrm{mg} / \mathrm{m} 2+ \\
\text { TBI } \rightarrow \text { MEL } 200 \mathrm{mg} / \mathrm{m} 2 \text { or CBV }\end{array}$ \\
\hline
\end{tabular}

Abbreviations: MEL: melphalan; FLU: fludarabine; CBV: cyclophosphamide, etoposide, BCNU; TBI: total body irradiation; DSS: Durie-Salmon Staging System; ISS: International staging system. 
autograft using MEL200 or not to undergo a second autograft [14]. For the purpose of this meta-analysis, only patients who received a second autograft were included in analysis.

For patients who received an auto-allo HCT approach, MEL200 was the preferred regimen for autografting in four studies [13-16]. RIC regimen of 2 Gy TBI was the preparative regimen in two studies $[13,15]$. Bjorkstrand et al. combined fludarabine with 2 Gy TBI [14], while the two remaining studies employed a RIC regimen with fludarabine/melphalan for allo-HCT [16,17]. No specific disease-risk eligibility criteria were required except in one study which limited enrollment to patients with deletion of chromosome 13q [16].

\section{Methodological quality}

Methodological quality of included studies is summarized in Table 2. Briefly, all five studies utilized biologic randomization. Four studies reported data on prognostic factors and groups were balanced for presence of associated prognostic risk factors [13-15,17,18] while one study did not report data on prognostic factors [16]. None of the studies reported whether all consecutive patients were enrolled. Four studies had at least 1:2 ratio of auto-allo HCT to auto-auto HCT patients while one study [17] had a 1:3.4 ratio. None of the five studies reported blinding of any study personnel. Four studies $[13-15,17,18]$ reported using the same reference time for assessing time dependent outcomes while one study [16] did not report a reference time. Three studies [13-15,18] reported outcomes according to intention-to-treat (ITT) and three studies $[14,15,17,18]$ reported harms for patients treated per protocol. One study reported a priori expected difference, pre-specified $\alpha$ and $\beta$ error, and sample size calculation [13].

\section{Benefits}

Summary of all evidence is presented in Table 3.

\section{Response rates}

Response data was reported per protocol in four studies and one study reported all outcomes according to both ITT and per protocol [14]. Two studies [14,17] used European Bone Marrow Transplantation (EBMT) criteria [21] for response assessment; one study [13] used International Uniform Response (IUR) Criteria [22], while the (more stringent $\mathrm{CR}$ and $\mathrm{PR}$ ) criteria used by Bruno et al. was described [15]. One study did not report how response was assessed [16].

As illustrated in Figure $2 \mathrm{~A}-\mathrm{C}$, the pooled results (three studies $[14,16,18]$ with 498 patients) showed no significant difference in overall response rate (ORR) between auto-allo HCT versus auto-auto HCT [risk ratio (RR) (95\% confidence interval $[\mathrm{CI}])=0.98(0.92-1.05), \mathrm{p}=0.66]$. There was low heterogeneity between pooled studies for the outcome of ORR $\left(I^{2}=25 \%\right)$. The pooled results for CR from five studies [13,14,16-18] (1130 patients) showed a statistically significant benefit in treatment with auto-allo HCT over auto-auto HCT [RR $(95 \% \mathrm{CI})=1.65$ (1.25-2.19), $\mathrm{p} \leq 0.001$ ] However, there was statistically significant heterogeneity among pooled studies $\left(\mathrm{I}^{2}=68 \%\right)$. Results for at least VGPR (one study [13] enrolling 522 patients) showed no significant difference between either treatment strategy [RR $(95 \% \mathrm{CI})=0.97$ (0.87-1.09), $\mathrm{p}=0.66]$.

\section{Event-free survival}

None of the studies reported definitions for event-free survival (EFS) or progression-free survival (PFS). For this analysis, EFS data was used when reported, otherwise PFS was substituted. As presented in Figure 3A, the pooled results from three studies [13,14,18] (1229 patients) which reported EFS according to ITT showed no significant difference between treatment with auto-allo HCT versus autoauto HCT [hazard ratio (HR) $(95 \% \mathrm{CI})=0.83(0.60$ 1.15), $\mathrm{p}=0.26$ ]. Pooled results for three studies $[14,17,18]$ (409 patients) which reported EFS per protocol also showed no significant difference in treatment with auto-allo HCT [HR $(95 \% \mathrm{CI})=0.78(0.58-1.05), \mathrm{p}=0.11]$ compared with auto-auto HCT. Heterogeneity among studies included in ITT analysis was significant $\left(\mathrm{I}^{2}=77 \%\right)$ while heterogeneity in per-protocol analysis was moderate $\left(\mathrm{I}^{2}=32 \%\right)$.

\section{Overall survival}

As illustrated in Figure 3B, the pooled results (three studies $[13,14,18]$ enrolling 1229 patients) for OS according to ITT showed no significant difference in treatment with auto-allo $\mathrm{HCT}$ versus auto-auto HCT [HR $(95 \% \mathrm{CI})=0.80(0.48-1.32), \mathrm{p}=0.39]$. The pooled results from two studies $[17,18]$ (214 patients) which reported OS per-protocol also showed no significant difference between the two treatment modalities [HR $(95 \% \mathrm{CI})=0.88(0.33-2.35), \mathrm{p}=0.79]$. There was a statistically significant heterogeneity whether OS was analyzed according to ITT $\left(\mathrm{I}^{2}=85 \%\right)$ or per-protocol $\left(\mathrm{I}^{2}=77 \%\right)$.

\section{Harms}

\section{Non-relapse mortality}

Pooled results from four studies [13,14,17,18] (1047 patients) showed NRM was significantly worse with an auto-allo HCT approach [RR $(95 \% \mathrm{CI})=3.55(2.17-5.80)$, $\mathrm{p}<0.00001]$ compared to auto-auto HCT (Figure 4A). There was no heterogeneity among included studies $\left(\mathrm{I}^{2}=0 \%\right)$. 
Table 2 Methodological quality of biologically randomized studies in tandem autologous versus autologous-allogeneic hematopoietic cell transplantation for patients with multiple myeloma

\begin{tabular}{|c|c|c|c|c|c|c|c|c|c|c|c|}
\hline \multirow[b]{2}{*}{ Study } & \multirow[b]{2}{*}{$\begin{array}{l}\text { Groups } \\
\text { balanced on } \\
\text { prognostic } \\
\text { factors }\end{array}$} & \multirow[b]{2}{*}{$\begin{array}{l}\text { All } \\
\text { consecutive } \\
\text { patients } \\
\text { included }\end{array}$} & \multicolumn{3}{|c|}{ Risk of bias } & \multirow[b]{2}{*}{$\begin{array}{l}\text { Same reference } \\
\text { time used for } \\
\text { both arms }\end{array}$} & \multirow[b]{2}{*}{$\begin{array}{l}\text { Report ITT } \\
\text { analysis of } \\
\text { benefits }\end{array}$} & \multirow[b]{2}{*}{$\begin{array}{l}\text { Report per } \\
\text { protocol } \\
\text { analysis of } \\
\text { harms }\end{array}$} & \multicolumn{2}{|c|}{ Risk of random error } & \multirow[b]{2}{*}{$\begin{array}{l}\text { Sample size } \\
\text { calculations } \\
\text { performed }\end{array}$} \\
\hline & & & $\begin{array}{l}\text { At least } 1: 2 \text { ratio of } \\
\text { auto-allo } \mathrm{HCT} \text { versus } \\
\text { auto-auto } \mathrm{HCT}\end{array}$ & $\begin{array}{l}\text { Description of } \\
\text { withdrawals/ } \\
\text { dropouts }\end{array}$ & $\begin{array}{l}\text { Blinding of } \\
\text { any study } \\
\text { personnel }\end{array}$ & & & & $\begin{array}{l}\text { A priori } \\
\text { expected } \\
\text { difference } \\
\text { stated }\end{array}$ & $\begin{array}{l}\text { a \& } \beta \\
\text { error } \\
\text { pre- } \\
\text { specified }\end{array}$ & \\
\hline $\begin{array}{l}\text { Björkstrand, } \\
2011\end{array}$ & yes & unclear & yes & no & no & yes & yes & yes & no & no & no \\
\hline $\begin{array}{l}\text { Giaccone, } \\
2011\end{array}$ & yes & unclear & yes & yes & no & yes & yes & yes & no & no & no \\
\hline Knop, 2009 & unclear & unclear & yes & no & no & unclear & unclear & unclear & no & no & no \\
\hline $\begin{array}{l}\text { Krishnan \& } \\
\text { Pasquini, } \\
2011\end{array}$ & yes & unclear & yes & yes & no & yes & yes & no & yes & yes & yes \\
\hline $\begin{array}{l}\text { Rosiñol, } \\
2008\end{array}$ & yes & unclear & no & yes & no & yes & no & yes & no & no & no \\
\hline
\end{tabular}


Table 3 Summary of evidence for tandem autologous versus autologous-allogeneic hematopoietic cell transplantation in patients with multiple myeloma

\begin{tabular}{|c|c|c|c|c|c|c|}
\hline \multicolumn{3}{|c|}{ Quality assessment } & \multicolumn{2}{|c|}{ No of patients } & \multicolumn{2}{|r|}{ Effect } \\
\hline $\begin{array}{l}\text { No of } \\
\text { studies }\end{array}$ & Design & $\begin{array}{l}\text { Risk of } \\
\text { bias }\end{array}$ & $\begin{array}{l}\text { Auto-allo } \\
\text { HCT }\end{array}$ & $\begin{array}{l}\text { Auto-auto } \\
\text { HCT }\end{array}$ & Relative $(95 \% \mathrm{Cl})$ & Absolute \\
\hline \multicolumn{7}{|c|}{ Overall response rate } \\
\hline 3 & $\begin{array}{l}\text { Biologically randomized } \\
\text { trials }\end{array}$ & $\begin{array}{l}\text { very } \\
\text { serious }^{1,2}\end{array}$ & $\begin{array}{c}248 / 275 \\
(90.2 \%)\end{array}$ & $\begin{array}{l}204 / 223 \\
(91.5 \%)\end{array}$ & RR 0.98 (0.92 to 1.05 ) & $\begin{array}{l}18 \text { fewer per } 1000 \text { (from } 73 \text { fewer to } \\
46 \text { more) }\end{array}$ \\
\hline \multicolumn{7}{|c|}{ Complete response } \\
\hline 5 & $\begin{array}{l}\text { Biologically randomized } \\
\text { trials }\end{array}$ & $\begin{array}{c}\text { very } \\
\text { serious }\end{array}$ & $\begin{array}{c}257 / 456 \\
(56.4 \%)\end{array}$ & $\begin{array}{c}254 / 674 \\
(37.7 \%)\end{array}$ & RR 1.65 (1.25 to 2.19$)$ & $\begin{array}{l}245 \text { more per } 1000 \text { (from } 94 \text { more to } \\
\qquad 448 \text { more) }\end{array}$ \\
\hline \multicolumn{7}{|c|}{ At least very good partial response } \\
\hline 1 & $\begin{array}{l}\text { Biologically randomized } \\
\text { trials }\end{array}$ & $\begin{array}{l}\text { very } \\
\text { serious }^{1,2}\end{array}$ & $\begin{array}{l}113 / 156 \\
(72.4 \%)\end{array}$ & $\begin{array}{c}272 / 366 \\
(74.3 \%)\end{array}$ & RR 0.97 (0.87 to 1.09) & $\begin{array}{l}22 \text { fewer per } 1000 \text { (from } 97 \text { fewer to } \\
67 \text { more) }\end{array}$ \\
\hline \multicolumn{7}{|c|}{ Event-free survival (ITT) } \\
\hline 3 & $\begin{array}{l}\text { Biologically randomized } \\
\text { trials }\end{array}$ & serious $^{1}$ & 414 & 815 & HR 0.83 (0.60 to 1.15) & - \\
\hline \multicolumn{7}{|c|}{ Event-free survival (per-protocol) } \\
\hline 4 & $\begin{array}{l}\text { Biologically randomized } \\
\text { trials }\end{array}$ & $\begin{array}{l}\text { very } \\
\text { serious }^{1,2}\end{array}$ & 174 & 235 & HR 0.78 (0.58 to 1.05$)$ & - \\
\hline \multicolumn{7}{|c|}{ Overall survival (ITT) } \\
\hline 3 & $\begin{array}{l}\text { Biologically randomized } \\
\text { trials }\end{array}$ & serious $^{1}$ & 414 & 815 & HR 0.80 (0.48 to 1.32) & - \\
\hline \multicolumn{7}{|c|}{ Overall survival (per-protocol) } \\
\hline 2 & $\begin{array}{l}\text { Biologically randomized } \\
\text { trials }\end{array}$ & $\begin{array}{l}\text { very } \\
\text { serious }^{1,2}\end{array}$ & 83 & 131 & HR 0.88 (0.33 to 2.35) & - \\
\hline \multicolumn{7}{|c|}{ Non-relapse mortality } \\
\hline 4 & $\begin{array}{c}\text { Biologically randomized } \\
\text { trials }\end{array}$ & serious $^{1}$ & $\begin{array}{l}50 / 363 \\
(13.8 \%)\end{array}$ & $\begin{array}{c}25 / 684 \\
(3.7 \%)\end{array}$ & RR 3.55 (2.17 to 5.80 ) & $\begin{array}{l}93 \text { more per } 1000 \text { (from } 43 \text { more to } \\
175 \text { more) }\end{array}$ \\
\hline \multicolumn{7}{|c|}{ Grade II-IV GVHD ${ }^{3}$} \\
\hline 4 & $\begin{array}{l}\text { Biologically randomized } \\
\text { trials }\end{array}$ & serious $^{1}$ & $\begin{array}{c}126 / 485 \\
(26 \%)\end{array}$ & - & $\begin{array}{c}\text { Proportion } 28.26 \text { (20.65 to } \\
36.55)\end{array}$ & - \\
\hline \multicolumn{7}{|c|}{ Chronic GVHD $^{3}$} \\
\hline 4 & $\begin{array}{l}\text { Biologically randomized } \\
\text { trials }\end{array}$ & serious $^{1}$ & $\begin{array}{c}206 / 356 \\
(57.9 \%)\end{array}$ & - & $\begin{array}{c}\text { Proportion } 60.69 \text { (50.65 to } \\
70.29)\end{array}$ & - \\
\hline
\end{tabular}

1 Selective outcome reporting; 2 Per-protocol reporting of benefits; 3 GVHD: graft-versus-host disease.

\section{Graft-versus-host disease}

Incidence of any acute graft-versus-host disease (GVHD) was reported in one study [14] (91 patients) and the proportion of patients undergoing auto-allo HCT with any GVHD was $30.77 \%$ (95\% CI 21.51-41.32). Incidence of grade II-IV GVHD was reported in four studies $[13,14,17,18]$ (363 patients), and the pooled proportion of patients undergoing auto-allo HCT with grade II-IV GVHD was 28.26\% (95\% CI 20.65-36.55; see Figure 4B). Heterogeneity among studies reporting grade II-IV GVHD was borderline $\left(\mathrm{I}^{2}=59 \%\right)$. Incidence of chronic GVHD was reported in four studies $[13,14,17,18]$ (356 patients), and the pooled proportion of patients undergoing auto-allo HCT with chronic GVHD was $60.69 \%$ (95\% CI 50.6570.29; Figure $4 C$ ). Heterogeneity among studies reporting chronic GVHD was significant $\left(\mathrm{I}^{2}=67 \%\right)$.

\section{Sensitivity analysis/subgroup analysis}

To assess robustness of the pooled results and explore possible reasons for heterogeneity, additional sensitivity and subgroup analyses were performed (see Table 4). To evaluate robustness of response outcomes, sensitivity analysis was performed according to response criteria (EBMT [21], IUR [22], non-EBMT/IUR [15], and not reported). There was no significant difference in ORR or CR regardless of criteria used. Sensitivity analysis for primary outcome of OS was performed according to all elements of risk of bias. Significant differences in pooled results were only detected when per protocol analysis of OS in a study (104 patients) which included at least 1:2 ratio of auto-allo HCT versus auto-auto HCT [HR $(95 \% \mathrm{CI})=0.55(0.32-0.94) \mathrm{p}=0.03]$ was compared with per protocol analysis of OS in a study (110) which did not 


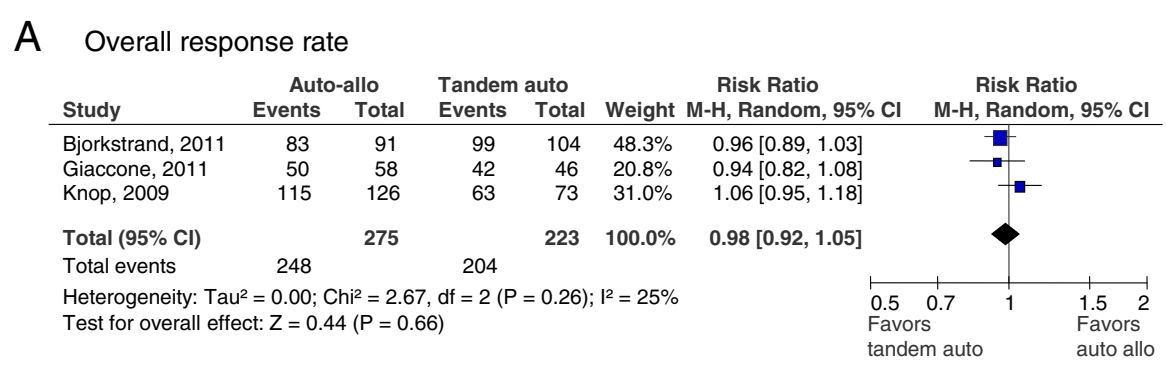

\section{B Complete response}

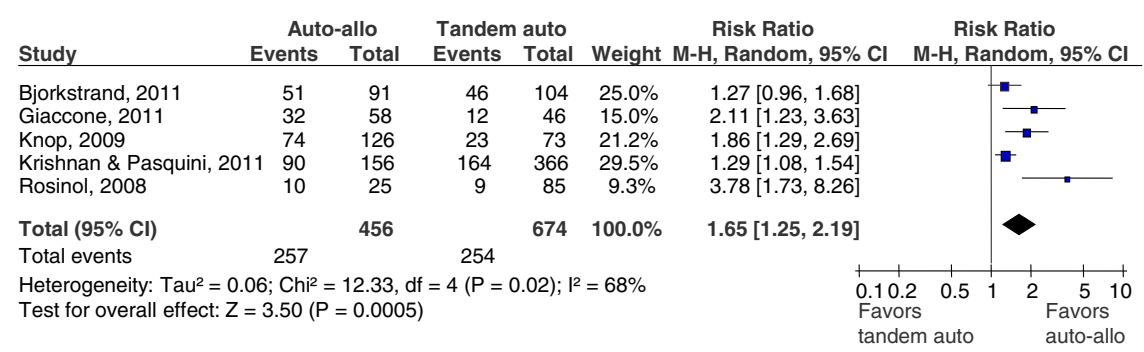

C At least very good partial response (CR + VGPR)

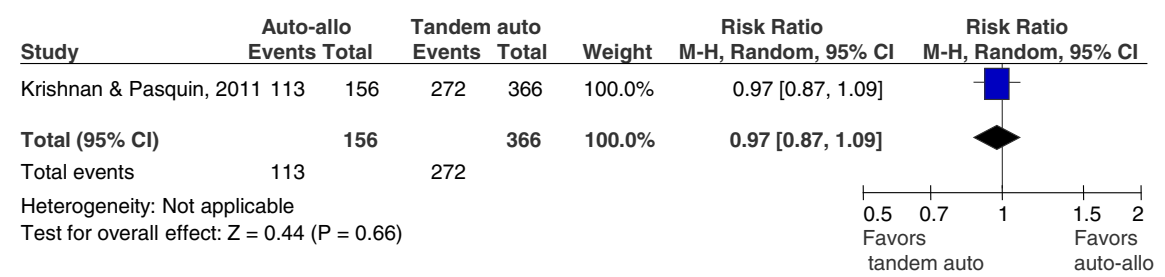

Figure 2 A through 2C: Forest plot for response rates. Overall (A), complete (B) or at least very good partial response (C). The summary estimate (risk ratio) from individual studies is indicated by rectangles with lines representing the $95 \%$ confidence intervals (Cls). The summary pooled estimate from all studies is represented by the diamond and the stretch of the diamond indicates the corresponding $95 \% \mathrm{Cl}$.

include at least 1:2 ratio of auto-allo HCT versus autoauto HCT [HR $(95 \%$ CI $)=1.51 \quad(0.70-3.27) \quad \mathrm{p}=0.30]$. Sensitivity analysis according to risk of bias did not explain reasons for observed heterogeneity of primary outcome. For risk of random error, while one study [13] (710 patients) which reported sample size calculations showed no difference in OS [HR $(95 \% \mathrm{CI})=1.24$ (0.94$1.64), \mathrm{p}=0.13]$, the pooled results from two studies $[14,18]$ (519 patients) which did not report sample size calculations showed a significant OS benefit with use of auto-allo HCT versus auto-auto HCT [HR $(95 \% \mathrm{CI})=0.64$ (0.43-0.95), $\mathrm{p}=0.03]$. There was statistically significant heterogeneity between the two studies which did not report sample size calculations $\left(\mathrm{I}^{2}=58 \%\right)$.

\section{Discussion}

Auto-HCT has been regarded as the standard of care for younger myeloma patients $[1,23]$. However, much controversy exists about the role and timing of allo-HCT in newly diagnosed MM. Our meta-analysis indicates despite higher
$\mathrm{CR}$ rates following an auto-allo HCT approach, there is no apparent improvement in OS, whether comparative analysis is performed as per-protocol or on ITT basis. This is likely explained by significantly higher NRM associated with RIC allo-HCT versus a second auto-HCT $[\mathrm{RR}(95 \% \mathrm{CI})=3.55$ (2.17-5.80), $\mathrm{p}<0.00001]$. Accordingly, further improvements in the auto-allo HCT approach will require strategies to significantly reduce NRM and augment anti-myeloma effects. Not surprising, significant cause of NRM in the auto-allo HCT arm resulted from development of acute and/or chronic GVHD in these patients. For instance, in the study by Krishnan et al. eight (13\%) of 60 deaths were attributed to GVHD [13]. Similarly, in the study by Rosiñol et al., three (75\%) of four cases of NRM were from complications of acute GVHD [17]. This suggests that future treatment strategies aimed at exploiting GVM effects, in auto-allo HCT approach, should avoid exacerbating GVHD at all costs. It is noteworthy that OS benefit with an auto-allo HCT approach is limited to studies using 2 Gy TBI-based conditioning regimens $[14,15]$, which 


\begin{tabular}{|c|c|c|c|c|c|c|c|c|}
\hline Study & $\log [\mathrm{HR}]$ & SE & $\begin{array}{c}\text { Auto-allo } \\
\text { Total }\end{array}$ & $\begin{array}{c}\text { Tandem auto } \\
\text { Total }\end{array}$ & Weight & $\begin{array}{l}\text { Hazard Ratio } \\
\text { IV, Random, } 95 \% \mathrm{CI}\end{array}$ & \multicolumn{2}{|c|}{$\begin{array}{c}\text { Hazard Ratio } \\
\text { IV, Random, } 95 \% \mathrm{CI}\end{array}$} \\
\hline Bjorkstrand, 2011 & -0.2357 & 0.1311 & 108 & 249 & $34.3 \%$ & $0.79[0.61,1.02]$ & \multirow[t]{2}{*}{$\square$} & \multirow[b]{3}{*}{+} \\
\hline Giaccone, 2011 & -0.4780 & 0.1739 & 80 & 82 & $29.4 \%$ & $0.62[0.44,0.87]$ & & \\
\hline Krishnan \& Pasquini, 2011 & 0.0953 & 0.1139 & 226 & 484 & $36.2 \%$ & $1.10[0.88,1.38]$ & & \\
\hline Total $(95 \% \mathrm{Cl})$ & & & 414 & 815 & $100.0 \%$ & $0.83[0.60,1.15]$ & & \\
\hline \multicolumn{7}{|c|}{ Test for overall effect: $Z=1.14(P=0.26)$} & $\begin{array}{l}0.5 \quad 0.7 \\
\text { Favors } \\
\text { auto-allo }\end{array}$ & $\begin{array}{lcl}1 & 1.5 & 2 \\
\text { Favors } \\
\text { tandem aut }\end{array}$ \\
\hline
\end{tabular}

\section{B Overall survival}

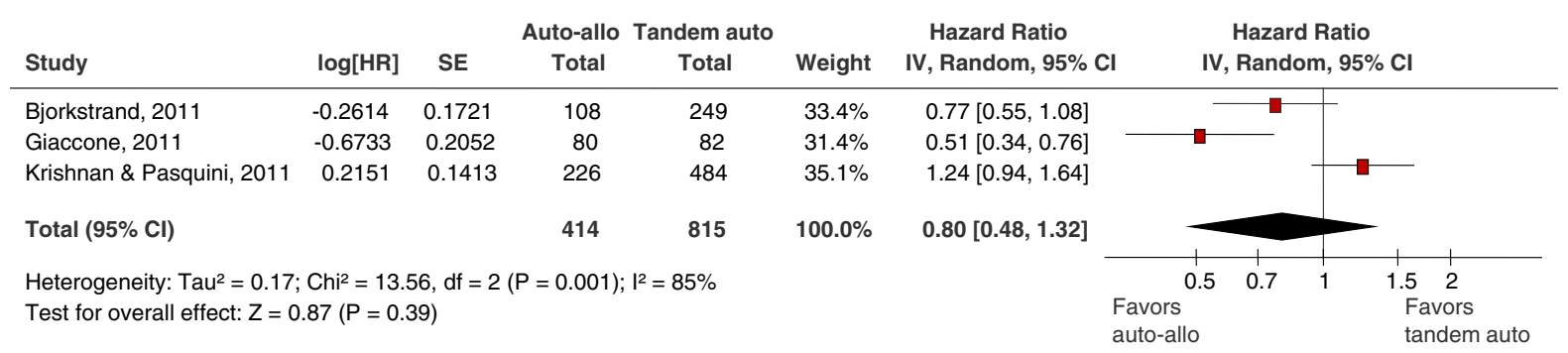

Figure $3 \mathrm{~A}$ and 3B: Forest plot for event-free survival according to intent-to-treat analysis (A) and overall survival (B). The summary estimate (hazard ratio) from individual studies is indicated by rectangles with lines representing the $95 \%$ confidence intervals (Cls). The summary pooled estimate from all studies is represented by the diamond and the stretch of the diamond indicates the corresponding $95 \% \mathrm{Cl}$.

has led to speculation [14] that the lack of survival benefit in other studies might relate to use of more intense conditioning which is associated with increased regimen-related toxicity and mortality in those studies $[16,17]$. It is important to indicate the largest trial by Krishnan et al. [13] used 2 Gy TBI conditioning but was also subject to referral bias, and to date has not reported any survival benefit.

Conceptually, auto-allo HCT approach combines the advantage of cytoreduction from HDT from the first autograft with the benefit of adoptive immunotherapy resulting from the donor $\mathrm{T}$ cell alloreactivity. Notwithstanding, in the study by Krishnan et al. 22 (37\%) of 60 deaths in the auto-allo HCT arm were still due to MM [13]. As a result, future strategies should aim at achieving deeper remissions, namely molecular remissions, or a state of minimal residual disease, prior to moving forward with allografting. This might entail evaluating novel potent therapies during the peri-allografting phase. Moreover, designing more effective regimens for allo-HCT, beyond 2 Gy TBI, is likely necessary to improve outcomes.

In regards to using auto-auto $\mathrm{HCT}$ as the control arm for comparison in these studies, one could argue that this approach is not yet considered the standard of care in all patients with newly diagnosed MM. In fact, outcomes from various studies comparing single auto-HCT versus tandem auto-auto approach have been discrepant $[7,24,25]$ and a published meta-analysis failed to show OS benefit with tandem autografts [8].

A major limitation of all studies comparing auto-auto HCT to auto-allo HCT is lack of detailed information about disease/genetic risk stratification. Only one study limited accrual to patients with deletion 13q detectable by FISH [16]. However prognostic significance of 13q deletion detected by FISH as opposed to conventional cytogenetics remains questionable [26]. Whether an auto-allo HCT approach might be beneficial for high-risk MM is not known, and should be further assessed in future trials [27-29]. We were not able to assess if auto-allo HCT approach might be beneficial for high risk myeloma patients as included studies did not report results according to risk categories for all outcomes. An individual patient data meta-analysis would be suitable to answer this question. Furthermore, the results are prone to outcome reporting bias as only three studies reported OS data according to ITT $[13,14,18]$ and another study reported data using per-protocol analysis only [17]. 


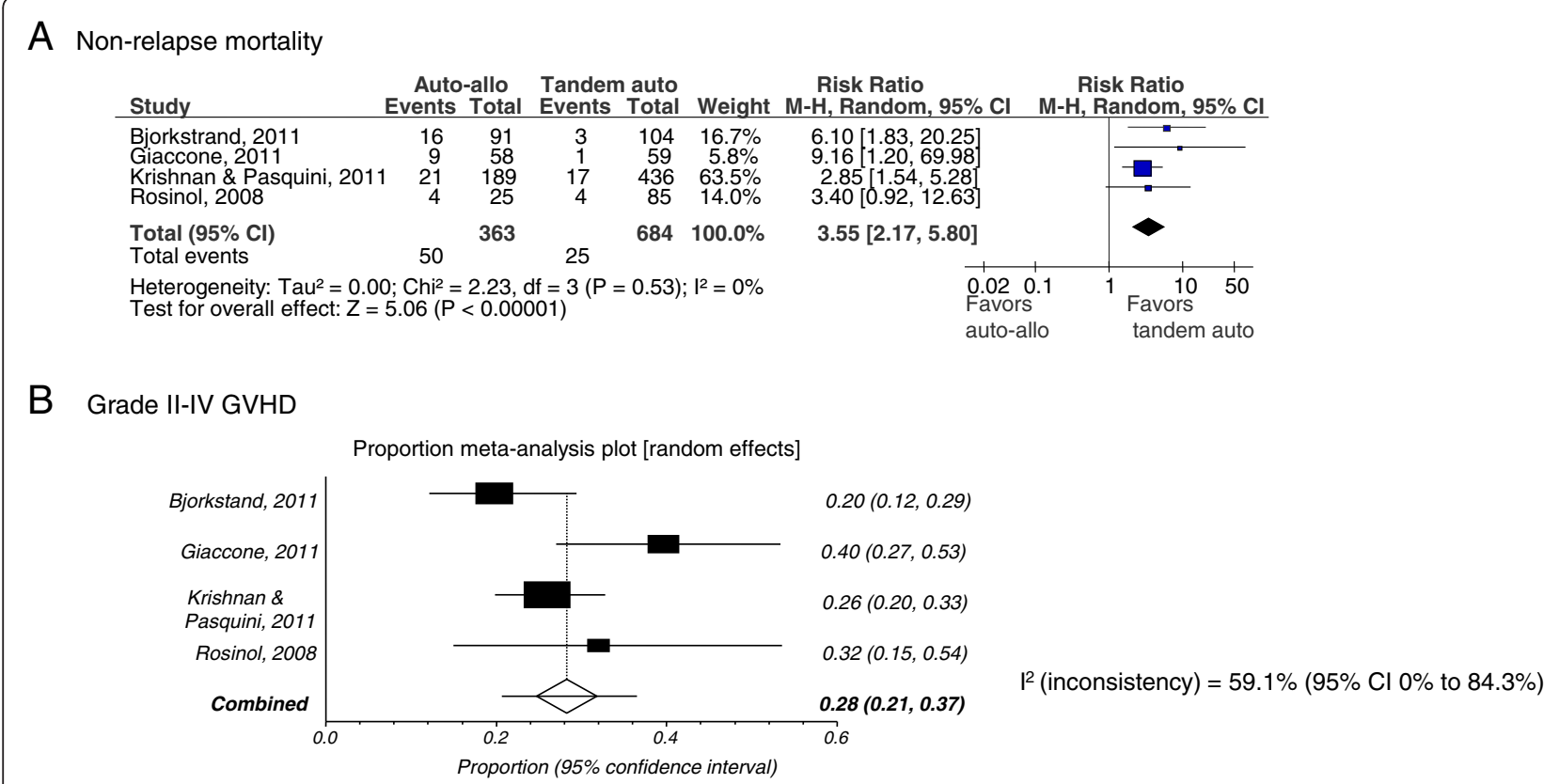

C Chronic GVHD

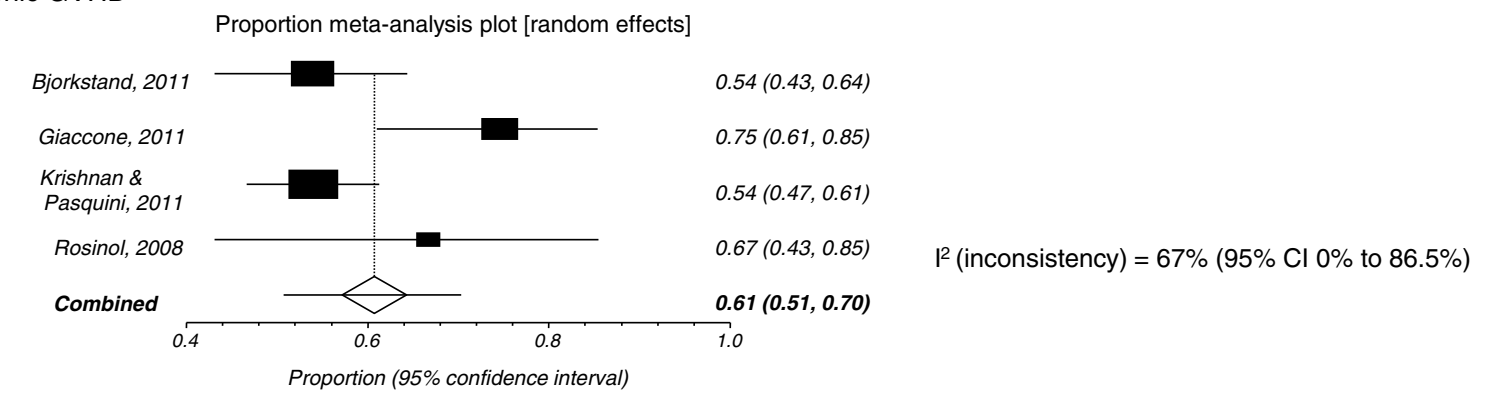

Figure 4 A through 4C: Forest plot for non-relapse mortality (A), grade II-IV graft versus-host disease (B) and chronic graft versus-host disease (C). The summary estimate (risk ratio/proportions) from individual studies is indicated by rectangles with lines representing the $95 \%$ confidence intervals (Cls). The summary pooled estimate from all studies is represented by the diamond and the stretch of the diamond indicates the corresponding $95 \% \mathrm{Cl}$. For the proportional meta-analysis the diamond represents the pooled summary estimates and the $95 \% \mathrm{Cl}$ is indicated by the line.

The findings are also somewhat different from the systematic review by Armeson et al. as we excluded a manuscript published by Garban et al. because it aimed at comparing two parallel trials (IFM99-03 and the IFM99-04) which enrolled allograft and autograft recipients separately [12]. The objectives of the IFM99-03 trial were to evaluate the feasibility and NRM of RIC allografting [19], whereas the primary end point of IFM99-04 was to compare CR rates achieved after the second auto HCT (with or without anti-IL-6 monoclonal antibody BE-8). Additionally, we excluded a cohort of high-risk patients reported by a study by Krishnan et al. because the original aim of this study was to assess progression-free survival among standard-risk patients [13]. The investigators reported only partial data on a smaller cohort of high-risk patients.

\section{Conclusions}

Efforts at identifying particular subgroups of patients with MM, based on prognostic clinical, biological, cytogenetic and genetic risk factors, which are likely to benefit from an auto-allo HCT approach is necessary to help refine the role of this approach in MM. At the present, totality of evidence suggests that an auto-allo HCT approach for patients with newly diagnosed myeloma should not be offered outside the setting of a clinical trial.

\section{Methods}

\section{Identification of eligible studies}

Any completed study in newly diagnosed MM patients comparing auto-auto HCT versus auto-allo HCT was eligible for inclusion in this systematic review. Studies 
Table 4 Sensitivity analyses by response criteria and significant elements of quality

\begin{tabular}{|c|c|c|c|c|c|c|c|}
\hline Subgroup & Outcome & Studies & Patients & HR or RR & $95 \% \mathrm{Cl}$ & Heterogeneity & Test of Interaction \\
\hline \multicolumn{8}{|c|}{ Tool used to capture response } \\
\hline EBMT criteria & \multirow[t]{3}{*}{ ORR (per-protocol) } & 1 & 195 & 0.96 & $(0.96-1.04)$ & NA & \multirow[t]{3}{*}{0.26} \\
\hline Non-EBMT/IUR criteria & & 1 & 104 & 0.94 & $(0.82-1.08)$ & NA & \\
\hline Criteria not reported & & 1 & 199 & 1.06 & $(0.95-1.18)$ & NA & \\
\hline EBMT criteria & \multirow[t]{4}{*}{ CR (per-protocol) } & 2 & 305 & 2.05 & $(0.71-5.98)$ & $85 \%$ & \multirow[t]{4}{*}{0.12} \\
\hline IUR criteria & & 1 & 522 & 1.29 & $(1.08-1.54)$ & NA & \\
\hline Non-EBMT/IUR criteria & & 1 & 104 & 2.11 & $(1.23-3.63)$ & NA & \\
\hline Criteria not reported & & 1 & 199 & 1.86 & $(1.29-1.54)$ & NA & \\
\hline \multicolumn{8}{|c|}{ At least 1:2 ratio of auto-allo HCT versus auto-auto HCT } \\
\hline Yes & \multirow[t]{2}{*}{ OS (per-protocol) } & 1 & 104 & 0.55 & $(0.32-0.94)$ & NA & \multirow[t]{2}{*}{0.04} \\
\hline No & & 1 & 110 & 1.51 & $(0.70-3.27)$ & NA & \\
\hline \multicolumn{8}{|c|}{ Description of withdrawals/dropouts } \\
\hline Yes & \multirow[t]{2}{*}{ OS (ITT) } & 2 & 872 & 0.81 & $(0.34-1.92)$ & $92 \%$ & \multirow[t]{2}{*}{0.93} \\
\hline No & & 1 & 357 & 0.77 & $(0.55-1.08)$ & NA & \\
\hline \multicolumn{8}{|c|}{ Report calculation of sample size } \\
\hline Yes & \multirow[t]{2}{*}{ OS (ITT) } & 1 & 710 & 1.24 & $(0.94-1.64)$ & NA & \multirow[t]{2}{*}{0.007} \\
\hline No & & 2 & 519 & 0.64 & $(0.43-0.95)$ & $58 \%$ & \\
\hline
\end{tabular}

Abbreviations: EBMT: European Group for Blood and Marrow Transplantation response criteria; IUR: International Uniform Response criteria; ORR: overall response rate; $C R$ : complete response; $O S$ : overall survival; ITT: intention-to-treat; $N A$ : not applicable.

which did not utilize biologic randomization or were indirect comparisons of tandem auto-auto HCT versus auto-allo HCT were excluded.

A systematic search of MEDLINE database thru Nov 5, 2011, and pertinent conference proceedings (American Society of Hematology, American Society of Clinical Oncology, European Hematology Association, American Society for Blood and Marrow Transplantation, and EBMT Group) was conducted to identify relevant publications. The following search strategy was used: ("Multiple Myeloma" [Mesh] AND "Transplantation, Autologous" [Mesh] AND "Transplantation, Homologous" [Mesh]). No search limits were applied based on language.

\section{Study selection and data extraction}

Two authors (M.A.K-D and M.H.) appraised the list of references and selected studies in consultation with other authors (T.R. and A.K.). Disagreements were resolved by consensus. Dual data extraction on clinical outcomes, treatment benefits and harms, and methodological quality of included studies was undertaken. Since biologic randomization is not similar to traditional randomized controlled trials, not all elements of risk of bias were applicable. For methodological quality, we extracted data on the following elements: comparability of two groups on all aspects except the intervention (e.g. disease stage, age, gender, etc.), enrollment of consecutive patients, enrollment of patients in auto-allo and auto-auto group in at least 1:2 ratio, description of withdrawals and dropouts (if any), blinding of study personnel and who was blinded (e.g. data collectors, outcome assessors etc.), comparability of reference time used for time-dependent outcomes between treatment groups and analysis according to ITT principle for benefits and per-protocol for adverse events. Clinical outcomes analyzed included: response rates (ORR, CR and VGPR), OS, EFS, NRM and GVHD. For purposes of this review, OS was considered the primary outcome; response rates, EFS, NRM and GVHD were considered secondary outcomes.

\section{Statistical analysis}

Dichotomous data were summarized using RR based on number of events and total number of patients and pooled under random-effects model. For time-to event data, HR and 95\% CI were extracted when reported. When authors did not report time-to-event estimates, we extracted data from publication using methods described by Tierney et al. [30]. Time-to-event data were pooled using generic inverse variance under randomeffects model. For analysis of proportional data, methods by Stuart et al. [31] were used to transform proportions into a quantity according to Freeman-Tukey variant of the arcsine square root transformed proportion [31]. Pooled proportion was calculated as a back-transform of the weighted mean of the transformed proportions, using random-effects model [31]. All data are reported with $95 \% \mathrm{CI}$. Calculation of the $\mathrm{I}^{2}$ statistic was used to test for heterogeneity. An $\mathrm{I}^{2}>50 \%$ was considered statistically significant heterogeneity [32]. To assess robustness of the pooled results and explore possible reasons for 
heterogeneity, additional sensitivity analyses/subgroup analyses were performed according to publication type, patient and disease characteristics, and methodological quality of included studies (risk of bias and random error). All analysis were performed using RevMan 5.1 [33] and StatsDirect [34] software. This work is reported according to the PRISMA guidelines [35].

\section{Abbreviations}

MM: Multiple myeloma; HDT: High-dose therapy; auto: Autologous; HCT: Hematopoietic cell transplantation; CR: Complete remission; IFM: Intergroupe Francophone du Myelome; OS: Overall survival; auto-auto: Tandem autologous; VGPR: Very good partial response; RIC: Reduced-intensity conditioning; auto-allo: Autologous followed by allogeneic; NRM: Non-relapse mortality; GVM: Graft-versus-myeloma; HOVON: Hemato-Oncologie voor Volwassenen Nederland;

ITT: Intention-to-treat; EBMT: European Bone Marrow Transplantation Group; ORR: Overall response rate; EFS: Event-free survival; GVHD: Graft-versus-host disease; RR: Risk ratio; HR: Hazard ratio; Cl: Confidence intervals; PRISMA: Preferred Reporting Items for Systematic Reviews and Meta-Analyses; IUR: International Uniform Response Criteria.

\section{Competing interests}

All authors have no competing interests that may be relevant to the submitted work.

\section{Authors' contributions}

MAKD, MH, BD, and AK were responsible for conception and design of this review. MAKD, MH, TR and AK performed the literature search and study selection. MAKD, MH, TR, and AK collected all data. MAKD, MH, TR, WB, BD, and $\mathrm{AK}$ contributed to the data analysis and interpretation of results. MAKD, $\mathrm{MH}$ and $\mathrm{AK}$ drafted the manuscript, MAKD, MH, TR, WB, BD, and AK revised the manuscript critically for important intellectual content. MAKD, MH, TR, $W B, B D$, and $A K$ approved the final version of the manuscript to be published. All authors read and approved the final manuscript.

\section{Previous presentation}

Parts of this manuscript have been presented as an oral presentation at the Annual Meeting of the European Group for Blood and Marrow Transplantation 2012 (Abstract 520).

\section{Author details}

'Blood and Marrow Transplantation Program, H. Lee Moffitt Cancer Center/ University of South Florida College of Medicine, Tampa, FL, USA. ${ }^{2}$ Bone Marrow Transplantation Program, Department of Internal Medicine, Division of Hematology-Oncology, American University of Beirut Medical Center, Beirut, Lebanon. ${ }^{3}$ Osborn Hematopoietic Malignancy and Transplantation Program, West Virginia University, Morgantown, WV, USA. ${ }^{4}$ Center for Evidence-Based Medicine and Health Outcomes Research, University of South Florida, Morsani College of Medicine, 12901 Bruce B. Downs Boulevard, MDC 27, Tampa, FL 33612, USA. ${ }^{5}$ Department of Medicine, Division of Oncology, University of Washington School of Medicine and Fred Hutchinson Cancer Center, Seattle, WA, USA. ${ }^{6}$ Department of Health Outcomes and Behavior, Moffitt Cancer Center, Tampa, FL, USA. 'Department of Hematologic Malignancies, Moffitt Cancer Center, Tampa, FL, USA.

Received: 30 November 2012 Accepted: 30 December 2012 Published: 4 January 2013

\section{References}

1. Attal M, Harousseau JL, Stoppa AM, Sotto JJ, Fuzibet JG, Rossi JF, Casassus P, Maisonneuve $\mathrm{H}$, Facon $\mathrm{T}$, Ifrah $\mathrm{N}$, et al: A prospective, randomized trial of autologous bone marrow transplantation and chemotherapy in multiple myeloma. Intergroupe francais du myelome. N Engl J Med 1996, 335:91-97.

2. Kumar SK, Rajkumar SV, Dispenzieri A, Lacy MQ, Hayman SR, Buadi FK, Zeldenrust SR, Dingli D, Russell SJ, Lust JA, et al: Improved survival in multiple myeloma and the impact of novel therapies. Blood 2008, 111:2516-2520
3. Richardson $P G$, Barlogie B, Berenson J, Singhal S, Jagannath S, Irwin D, Rajkumar SV, Srkalovic G, Alsina M, Alexanian R, et al: A phase 2 study of bortezomib in relapsed, refractory myeloma. N Eng/ J Med 2003, 348:2609-2617.

4. Richardson PG, Schlossman RL, Weller E, Hideshima T, Mitsiades C, Davies F, LeBlanc R, Catley LP, Doss D, Kelly K, et al: Immunomodulatory drug CC-5013 overcomes drug resistance and is well tolerated in patients with relapsed multiple myeloma. Blood 2002, 100:3063-3067.

5. Singhal S, Mehta J, Desikan R, Ayers D, Roberson P, Eddlemon P, Munshi N, Anaissie E, Wilson C, Dhodapkar M, et al: Antitumor activity of thalidomide in refractory multiple myeloma. N Engl J Med 1999, 341:1565-1571.

6. Barlogie B, Jagannath S, Desikan KR, Mattox S, Vesole D, Siegel D, Tricot G, Munshi N, Fassas A, Singhal S, et al: Total therapy with tandem transplants for newly diagnosed multiple myeloma. Blood 1999, 93:55-65.

7. Attal M, Harousseau JL, Facon T, Guilhot F, Doyen C, Fuzibet JG, Monconduit M, Hulin C, Caillot D, Bouabdallah R, et al: Single versus double autologous stem-cell transplantation for multiple myeloma. N Engl J Med 2003, 349:2495-2502.

8. Kumar A, Kharfan-Dabaja MA, Glasmacher A, Djulbegovic B: Tandem versus single autologous hematopoietic cell transplantation for the treatment of multiple myeloma: a systematic review and meta-analysis. J Natl Cancer Inst 2009, 101:100-106.

9. Badros A, Barlogie B, Siegel E, Cottler-Fox M, Zangari M, Fassas A, Morris C, Anaissie E, Van Rhee F, Tricot G: Improved outcome of allogeneic transplantation in high-risk multiple myeloma patients after nonmyeloablative conditioning. J Clin Oncol 2002, 20:1295-1303.

10. Gahrton G, Svensson H, Cavo M, Apperly J, Bacigalupo A, Björkstrand B, Blade J, Cornelissen J, de Laurenzi A, Facon T, et al: Progress in allogenic bone marrow and peripheral blood stem cell transplantation for multiple myeloma: a comparison between transplants performed 1983-93 and 1994-8 at European group for blood and marrow transplantation centres. Br J Haematol 2001, 113:209-216.

11. Kumar S, Zhang MJ, Li P, Dispenzieri A, Milone GA, Lonial S, Krishnan A, Maiolino A, Wirk B, Weiss B, et al: Trends in allogeneic stem cell transplantation for multiple myeloma: a CIBMTR analysis. Blood 2011, 118:1979-1988.

12. Armeson KE, Hill EG, Costa $\mathrm{L}$ : Tandem autologous vs autologous plus reduced intensity allogeneic transplantation in the upfront management of multiple myeloma: meta-analysis of trials with biological assignment. Bone Marrow Transplant 2012, 22964593.

13. Krishnan A, Pasquini MC, Logan B, Stadtmauer EA, Vesole DH, Alyea E 3rd, Antin JH, Comenzo R, Goodman S, Hari P, et al: Autologous haemopoietic stem-cell transplantation followed by allogeneic or autologous haemopoietic stem-cell transplantation in patients with multiple myeloma (BMT CTN 0102): a phase 3 biological assignment trial. Lancet Oncol 2011, 12:1195-1203.

14. Björkstrand B, lacobelli S, Hegenbart U, Gruber A, Greinix H, Volin L, Narni F, Musto P, Beksac M, Bosi A, et al: Tandem autologous/reduced-intensity conditioning allogeneic stem-cell transplantation versus autologous transplantation in myeloma: long-term follow-up. J Clin Oncol 2011, 29:3016-3022

15. Bruno B, Rotta M, Patriarca F, Mordini N, Allione B, Carnevale-Schianca F, Giaccone L, Sorasio R, Omede P, Baldi I, et al: A comparison of allografting with autografting for newly diagnosed myeloma. N Engl J Med 2007, 356:1110-1120

16. Knop S, Liebisch P, Hebart H, Holler E, Engelhardt M, Bargou R, Metzner B, Peest $D$, Aulitzky W, Wandt $H$, et al: Allogeneic stem cell transplant versus tandem high-dose melphalan for front-line treatment of deletion $13 q 14$ myeloma - an interim analysis of the german DSMM V trial. Blood 2011, 114:51.

17. Rosiñol L, Perez-Simon JA, Sureda A, de la Rubia J, de Arriba F, Lahuerta JJ, Gonzalez JD, Diaz-Mediavilla J, Hernandez B, Garcia-Frade J, et al: A prospective PETHEMA study of tandem autologous transplantation versus autograft followed by reduced-intensity conditioning allogeneic transplantation in newly diagnosed multiple myeloma. Blood 2008, 112:3591-3593

18. Giaccone L, Storer B, Patriarca F, Rotta M, Sorasio R, Allione B, Carnevale-Schianca F, Festuccia M, Brunello L, Omede P, et al: Long-term follow-up of a comparison of nonmyeloablative allografting with autografting for newly diagnosed myeloma. Blood 2011, 117:6721-6727.

19. Garban F, Attal M, Michallet M, Hulin C, Bourhis JH, Yakoub-Agha I, Lamy T, Marit G, Maloisel F, Berthou C, et al: Prospective comparison of autologous 
stem cell transplantation followed by dose-reduced allograft (IFM99-03 trial) with tandem autologous stem cell transplantation (IFM99-04 trial) in high-risk de novo multiple myeloma. Blood 2006, 107:3474-3480.

20. Lokhorst H, Sonneveld P, Holt B, Oers M, Raymakers R, Zweegman S, Minnema M, Zijlmans M: Donor versus no donor analysis of newly diagnosed myeloma patients included in the HOVON 50/54 study. Blood 2008, 112:461.

21. Blade J, Samson D, Reece D, Apperley J, Björkstrand B, Gahrton G, Gertz M, Giralt S, Jagannath S, Vesole D: Criteria for evaluating disease response and progression in patients with multiple myeloma treated by high-dose therapy and haemopoietic stem cell transplantation. Myeloma subcommittee of the EBMT. European group for blood and marrow transplant. Br J Haematol 1998, 102:1115-1123.

22. Durie BG, Harousseau JL, Miguel JS, Blade J, Barlogie B, Anderson K, Gertz M, Dimopoulos M, Westin J, Sonneveld P, et al: International uniform response criteria for multiple myeloma. Leukemia 2006, 20:1467-1473.

23. Child JA, Morgan GJ, Davies FE, Owen RG, Bell SE, Hawkins K, Brown J. Drayson MT, Selby PJ: High-dose chemotherapy with hematopoietic stem-cell rescue for multiple myeloma. N Engl J Med 2003, 348:1875-1883.

24. Cavo M, Tosi P, Zamagni E, Cellini C, Tacchetti P, Patriarca F, Di Raimondo F, Volpe E, Ronconi S, Cangini D, et al: Prospective, randomized study of single compared with double autologous stem-cell transplantation for multiple myeloma: bologna 96 clinical study. J Clin Oncol 2007, 25:2434-2441

25. Sonneveld P, van der Holt B, Segeren CM, Vellenga E, Croockewit AJ, Verhoe GE, Cornelissen JJ, Schaafsma MR, van Oers MH, Wijermans PW, et al: Intermediate-dose melphalan compared with myeloablative treatment in multiple myeloma: long-term follow-up of the dutch cooperative group HOVON 24 trial. Haematologica 2007, 92:928-935.

26. Avet-Loiseau H, Attal M, Moreau P, Charbonnel C, Garban F, Hulin C, Leyvraz S, Michallet M, Yakoub-Agha I, Garderet L, et al: Genetic abnormalities and survival in multiple myeloma: the experience of the intergroupe francophone du myelome. Blood 2007, 109:3489-3495.

27. Dispenzieri A: Is there a future for auto-allo HSCT in multiple myeloma? Lancet Oncol 2011, 12:1176-1177.

28. Dispenzieri A, Rajkumar SV, Gertz MA, Fonseca R, Lacy MQ, Bergsagel PL, Kyle RA, Greipp PR, Witzig TE, Reeder CB, et al: Treatment of newly diagnosed multiple myeloma based on mayo stratification of myeloma and risk-adapted therapy (mSMART): consensus statement. Mayo Clin Proc 2007, 82:323-341.

29. Kumar SK, Mikhael JR, Buadi FK, Dingli D, Dispenzieri A, Fonseca R, Gertz MA, Greipp PR, Hayman SR, Kyle RA, et al: Management of newly diagnosed symptomatic multiple myeloma: updated mayo stratification of myeloma and risk-adapted therapy (mSMART) consensus guidelines. Mayo Clin Proc 2009, 84:1095-1110.

30. Tierney JF, Stewart LA, Ghersi D, Burdett S, Sydes MR: Practical methods for incorporating summary time-to-event data into meta-analysis. Trials 2007, 8:16.

31. Stuart A, Ord K: Kendallıs advanced theory of statistics: Wiley; 1994.

32. Higgins JPT, Green S: Cochrane Handbook for Systematic Reviews of Interventions, Version 5.1.0 edition: The Cochrane Collaboration; 2011.

33. RevMan: Review Manager: The Cochrane Collaboration-available on the world wide web. 51st edition. http://www.cochrane.org/cochrane/revman.htm.

34. StatsDirect Ltd: StatsDirect statistical software. England: Stats Direct Ltd; 2008. http://www.statsdirect.com

35. Liberati A, Altman DG, Tetzlaff J, Mulrow C, Gotzsche PC, loannidis JP, Clarke M, Devereaux PJ, Kleijnen J, Moher D: The PRISMA statement for reporting systematic reviews and meta-analyses of studies that evaluate health care interventions: explanation and elaboration. J Clin Epidemiol 2009, 62:e1-34.

doi:10.1186/1756-8722-6-2

Cite this article as: Kharfan-Dabaja et al:: Comparative efficacy of tandem autologous versus autologous followed by allogeneic hematopoietic cell transplantation in patients with newly diagnosed multiple myeloma: a systematic review and meta-analysis of randomized controlled trials. Journal of Hematology \& Oncology 2013 6:2.

\section{Submit your next manuscript to BioMed Central and take full advantage of:}

- Convenient online submission

- Thorough peer review

- No space constraints or color figure charges

- Immediate publication on acceptance

- Inclusion in PubMed, CAS, Scopus and Google Scholar

- Research which is freely available for redistribution

Submit your manuscript at www.biomedcentral.com/submit
Biomed Central 